\title{
Research on the evaluation model of Higher Vocational Teachers' ability based on Analytic Hierarchy Process
}

\author{
Haiwei Peng ${ }^{1}$, Xiaohui Peng ${ }^{2}$ and Xiaogao Wang ${ }^{3, a, *}$ \\ ${ }^{1}$ Shanwei Vocation \& Technical College. Shanwei, China \\ ${ }^{2}$ Army 73151. Xiamen, China \\ ${ }^{3}$ Army 73151. Xiamen, China \\ a e-mail: wangxiaogao516@sina.com
}

Keywords: Analytic Hierarchy Process, Higher vocational teachers, Evaluation model

\begin{abstract}
This article aims at the evaluation of the competence of higher vocational teachers through data collection, questionnaire investigation, mathematical modelling and other research methods. First, we expounded the necessity and importance of the evaluation of teachers' ability based on the analysis of the meaning and the present situation of teachers' ability. Then, we constructed an evaluation index system based on five first-level indicators and 20 second-level indicators, and an evaluation model based on analytic hierarchy process of higher vocational teachers' ability. The results showed that compared with other models, our model has the advantages of clear structure, strong level and simple calculation, which can provide reference for the selection and evaluation of higher vocational teachers.
\end{abstract}

\section{Introduction}

The ability of higher vocational teachers refers to the psychological characteristics of teachers in the teaching and research activities. In order to achieve a certain goal, the dynamic power or practical skills are required in education, teaching and scientific research. The evaluation of teacher competence in higher vocational education is an important part in teaching management and human resource management in higher vocational colleges. The effective evaluation model can make the higher vocational teachers have a more objective understanding of their ability, and inspire the enthusiasm of teachers to improve the work efficiency. And provide the basis for the selection, assessment, encouragement and training of teachers in higher vocational education [1].

\section{Higher Vocational Teachers' Ability Evaluation Index Selection}

In order to ensure the comprehensiveness and representativeness of the index selection, five kinds of first-level indicators are selected as the index system of the competence evaluation of higher vocational teachers by means of access to information and issuing questionnaires, respectively, for the professional basis ability, theoretical teaching ability, training teaching ability, teaching methods and means of ability and teaching and research ability, as shown in Figure 1. [2] 


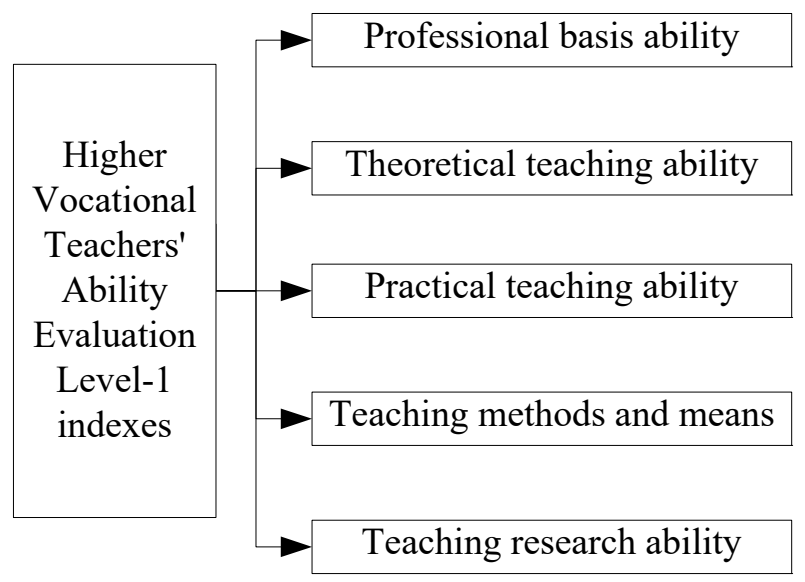

Figure 1 Higher Vocational Teachers' Ability Evaluation Level-1 indexes

In order to improve the accuracy of the evaluation and the measurability of the data, the primary indicators are refined into more specific secondary indicators, see Table 1.

Table 1 Evaluation Index System of Higher Vocational Teachers

\begin{tabular}{ll}
\hline Level-1 index & Level-2 index \\
\hline & Professional moral ability $A_{1}$ \\
& Modern vocational education theory $A_{2}$ \\
Professional basic ability $A$ & Ability of educational theory $A_{3}$ \\
& Ideological education and psychological counselling $A_{4}$ \\
& Teamwork ability $A_{5}$ \\
\hline
\end{tabular}

Curriculum design ability $B_{1}$

Reorganization of teaching content and teaching material compiling ability $B_{2}$

Theoretical teaching ability $B \quad$ Teaching organization ability $B_{3}$

Classroom control ability $B_{4}$

Language expression ability $B_{5}$

Practical curriculum design ability $C_{1}$

$\begin{array}{ll}\text { Practical teaching ability } C & \text { Practical training guidance ability } C_{2} \\ \text { Practical teaching organization ability } C_{3}\end{array}$

Practice teaching evaluation $C_{4}$

Teaching method application ability $D_{1}$

Teaching methods and means $D \quad$ Modern educational technology application ability $D_{2}$

Educational information and the application ability of computer network technology $D_{3}$

Writing ability $E_{1}$

Teaching research ability $E \quad$ Information acquisition and processing ability $E_{2}$

Comprehensive analysis ability $E_{3}$

From the structural point of view, the above evaluation index system reflects the characteristics of higher vocational education, highlighting the evaluation focus. The setting of the Level-1 index emphasizes the evaluation of the teacher's theory teaching ability, the training ability and the teaching method and the means of using the ability. The setting of the Level-2 index focuses on the 
evaluation of teachers' teaching design ability, training ability, teaching organization ability and classroom control ability. At the same time, according to the characteristics of vocational students added to the teacher ideological education and psychological ability to assess the specific indicators [3].

\section{Establishment and Solution of Higher Vocational Teachers' Ability Evaluation Model Based on Analytic Hierarchy Process}

\subsection{Determination of index weight}

In this paper, we use the analytic hierarchy process to determine the relative weight. The AHP is an effective treatment method of practical decision problem proposed by T.L.Saaty et al in 1970s, also called the hierarchical analysis method, system analysis method is hierarchical and a combination of qualitative and quantitative. [4].

\subsubsection{Determination of the weight of the Level-1 Index}

Step1: Constructing pairwise comparison matrix $W$.

By using the methods of expert consultation and questionnaire, the evaluation indexes of each level were compared with their levels. The pairwise comparison matrix is constructed by using 1-9 scale [5]. For example: relative to target $A$, if the degree of influence between $A_{1}$ and $A_{2}$ is the same, then the value is 1 ; If $A_{1}$ is slightly more important than $A_{2}$, then $A_{1}$ is $3, A_{2}$ is $1 / 3$; if $A_{1}$ is more important than $A_{2}$, then $A_{1}$ is $5, A_{2}$ is $1 / 5$; If $A_{1}$ is significantly more important than $A_{2}$, then $A_{1}$ is $7, A_{2}$ is $1 / 7$; If the influence of $A_{1}$ and $A_{2}$ is between the above three levels, then the value of $A_{1}$ is $2,4,6, A_{2}$ is $1 / 2,1 / 4,1 / 6$.

Step2: Using the summation method to calculate the relative weight of the index $\omega$ :

$$
W \stackrel{\text { Column vector normalization }}{\longrightarrow} L W \stackrel{\text { Sum by line }}{\longrightarrow} A W \stackrel{\text { normalization }}{\longrightarrow} \omega 1
$$

Step3: Consistency test of relative weight of indicators.

In order to make the relative weights of the five Level-1 indexes calculated by the pairwise comparison matrix can be used, the consistency test must be carried out. The consistency ratio is expressed in $C R$. If $C R>1$, The consistency test passed.

$$
C R=\frac{C I}{R I}
$$

Among them, $C I=\frac{\lambda_{\max }-n}{n-1}, n$ is the number of index elements, $\lambda_{\max }$ is the largest eigenvalue of the pairwise comparison matrix, $\lambda_{\max }=\frac{1}{n} \sum_{i=1}^{n} \frac{(A W)_{i}}{(\omega 1)_{i}}, \quad R I$ can be obtained by checking the random consistency index.

\subsubsection{Determination of the weight of the Level-2 Index}

The relative weight $\omega 2$ of the two level indexes relative to the first level index can be determined by the method of determining the relative weight of the first grade index.

\subsubsection{Determination of the comprehensive weight of Level-2 Index}

The secondary weight of the Level-2 Index is determined by multiplying the relative weights of the Level-1 Indexes by the relative weights of the Level-2 Indexes relative to the Level-1 Indexes. 


$$
\omega z=\sum_{i=1}^{n} \omega 1(i) \bullet \omega 2(i)
$$

\subsection{Model establishment}

Using the analytic hierarchy process to determine the relative weight of the indicators in the evaluation index system of teachers' ability in higher vocational colleges, the mathematical model of $P$ :

$$
P=\sum_{i=1}^{n} \omega z(i) \bullet P(i)
$$

Among them, $P_{i}$ represents the actual measured value of each two indicators.

\subsection{Model solution}

Through the issuance of questionnaires, interviews and access to archival information, randomly selected 10 in-service teachers who are in vocational and technical college to its 20 secondary indicators to evaluate the results are as follows:

\begin{tabular}{|c|c|c|c|c|c|c|c|c|c|c|c|}
\hline \multicolumn{2}{|c|}{ sample } & 01 & 02 & 03 & 04 & 05 & 06 & 07 & 08 & 09 & 10 \\
\hline \multirow{5}{*}{$A$} & $A_{1}$ & 89 & 79 & 91 & 94 & 91 & 89 & 76 & 90 & 96 & 76 \\
\hline & $A_{2}$ & 92 & 82 & 75 & 72 & 71 & 96 & 82 & 89 & 84 & 71 \\
\hline & $A_{3}$ & 98 & 98 & 87 & 89 & 76 & 75 & 82 & 84 & 95 & 93 \\
\hline & $A_{4}$ & 97 & 94 & 71 & 78 & 81 & 76 & 83 & 89 & 96 & 73 \\
\hline & $A_{5}$ & 79 & 97 & 92 & 95 & 81 & 71 & 72 & 96 & 90 & 97 \\
\hline \multirow{5}{*}{ B } & $B_{1}$ & 98 & 89 & 90 & 99 & 83 & 98 & 73 & 78 & 96 & 81 \\
\hline & $B_{2}$ & 89 & 75 & 70 & 85 & 86 & 74 & 86 & 82 & 82 & 70 \\
\hline & $B_{3}$ & 91 & 96 & 78 & 97 & 94 & 91 & 88 & 73 & 70 & 91 \\
\hline & $B_{4}$ & 95 & 92 & 91 & 93 & 95 & 72 & 88 & 72 & 97 & 96 \\
\hline & $B_{5}$ & 93 & 84 & 74 & 72 & 95 & 86 & 98 & 73 & 72 & 75 \\
\hline \multirow{4}{*}{$C$} & $C_{1}$ & 86 & 99 & 99 & 70 & 82 & 77 & 86 & 71 & 91 & 77 \\
\hline & $C_{2}$ & 77 & 72 & 88 & 96 & 99 & 93 & 72 & 90 & 90 & 74 \\
\hline & $C_{3}$ & 81 & 81 & 90 & 76 & 94 & 92 & 88 & 85 & 74 & 92 \\
\hline & $C_{4}$ & 72 & 82 & 83 & 79 & 90 & 76 & 96 & 80 & 92 & 77 \\
\hline \multirow{3}{*}{$D$} & $D_{1}$ & 85 & 88 & 78 & 70 & 99 & 89 & 94 & 83 & 78 & 91 \\
\hline & $D_{2}$ & 88 & 96 & 97 & 92 & 70 & 76 & 90 & 72 & 84 & 73 \\
\hline & $D_{3}$ & 78 & 70 & 77 & 85 & 97 & 96 & 92 & 97 & 93 & 86 \\
\hline \multirow{3}{*}{$E$} & $E_{1}$ & 81 & 95 & 78 & 77 & 99 & 96 & 91 & 99 & 77 & 79 \\
\hline & $E_{2}$ & 80 & 80 & 90 & 97 & 87 & 72 & 91 & 86 & 72 & 92 \\
\hline & $E_{3}$ & 92 & 72 & 77 & 79 & 86 & 85 & 71 & 88 & 83 & 91 \\
\hline
\end{tabular}

Table 2 Evaluation index system of Higher Vocational Teachers

Using the analytic hierarchy process to determine the index weight, see Table 3: 
Table 3 Evaluation index and weight of Higher Vocational Teachers

\begin{tabular}{|c|c|c|c|c|c|c|c|c|c|c|c|}
\hline \multicolumn{2}{|c|}{$\begin{array}{l}\text { Level-1 index } \\
\text { and weight }\end{array}$} & \multicolumn{10}{|c|}{ Level-1 index and weight / Level-2 index comprehensive weight } \\
\hline$A$ & 0.2428 & $A_{1}$ & $\begin{array}{l}0.4302 \\
0.1045\end{array}$ & $A_{2}$ & $\begin{array}{l}0.1924 \\
0.0467\end{array}$ & $A_{3}$ & $\begin{array}{l}0.0982 \\
0.0238\end{array}$ & $A_{4}$ & $\begin{array}{l}0.0513 \\
0.0125\end{array}$ & $A_{5}$ & $\begin{array}{l}0.2279 \\
0.0553\end{array}$ \\
\hline$B$ & 0.323 & $B_{1}$ & $\begin{array}{l}0.2681 \\
0.0866\end{array}$ & $B_{2}$ & $\begin{array}{l}0.2587 \\
0.0836\end{array}$ & $B_{3}$ & $\begin{array}{l}0.1751 \\
0.0566\end{array}$ & $B_{4}$ & $\begin{array}{l}0.189 \\
0.061\end{array}$ & $B_{5}$ & $\begin{array}{c}0.109 \\
0.0352\end{array}$ \\
\hline$C$ & 0.303 & $C_{1}$ & $\begin{array}{c}0.305 \\
0.0924\end{array}$ & $C_{2}$ & $\begin{array}{l}0.3618 \\
0.1096\end{array}$ & $C_{3}$ & $\begin{array}{l}0.2539 \\
0.0769\end{array}$ & $C_{4}$ & $\begin{array}{c}0.0793 \\
0.024\end{array}$ & & \\
\hline$D$ & 0.0538 & $D_{1}$ & $\begin{array}{c}0.525 \\
0.0282\end{array}$ & $D_{2}$ & $\begin{array}{c}0.2982 \\
0.016\end{array}$ & $D_{3}$ & $\begin{array}{l}0.1768 \\
0.0095\end{array}$ & & & & \\
\hline E & 0.0774 & $E_{1}$ & $\begin{array}{c}0.15 \\
0.0116\end{array}$ & $E_{2}$ & $\begin{array}{c}0.34 \\
0.0263\end{array}$ & $E_{3}$ & $\begin{array}{c}0.51 \\
0.0395\end{array}$ & & & & \\
\hline
\end{tabular}

According to the evaluation index system of teachers' vocational competence and the weight parameters of each index, the author uses the established model to evaluate the competence of 10 higher vocational teachers, as shown in Table 4:

Table 4 Comparison of the Evaluation Results of 10 Teachers' Competence

\begin{tabular}{ccccccccccc}
\hline sample & 01 & 02 & 03 & 04 & 05 & 06 & 07 & 08 & 09 & 10 \\
\hline $\begin{array}{c}\text { Composite score } \\
\begin{array}{c}\text { Gray correlation } \\
\text { degree evaluation } \\
\text { model score }\end{array}\end{array}$ & 0.81 .24 & 84.92 & 85.79 & 86.47 & 88.46 & 84.91 & 82.19 & 82.88 & 86.65 & 81.91 \\
\hline
\end{tabular}

\section{Conclusions}

In the model, the pairwise comparison matrix of each level index can be consistent with the consistency test, the model results and the grey relational model based on the higher vocational teacher ability evaluation model compared to 10 higher vocational teachers ranked basically the same. The evaluation model based on analytic hierarchy process has the advantages of clear structure, strong level, simple calculation and qualitative and quantitative combination. The evaluation system of teachers' professional competence can comprehensively and scientifically and objectively reflect the capacity of teachers in higher vocational colleges.

\section{References}

[1] Qing Wu (2016) A Summary of the Research on the Framework of Teachers' Professional Competence Evaluation System. Technology and market.

[2] Jingyong Bai (2011) Design of Evaluation System of University Teachers' Scientific Research Ability Based on Professional Growth. Continuing education research.

[3] Yunhong Zou (2013) On the Main Problems and Countermeasures of Professional Ability of Higher Vocational Teachers. Journal of Wuxi Vocational and Technical College of Commerce.

[4] Laicheng Wu, Xinchun Dong (2015) Research on Evaluation Index and Model of Teachers' Professional Ability in Higher Vocational Colleges. Chinese Journal of Forestry Education.

[5] Bingjiang Zhang (2014) Analytic Hierarchy Process and Its Application. Electronic Industry Press, Beijing. 